\title{
Keeping Our Mouths Shut: The Fear and Racialized Self-Censorship of British Healthcare Professionals in PREVENT Training
}

\author{
Tarek Younis $^{1}$ (D) Sushrut Jadhav ${ }^{2}$
}

Published online: 5 April 2019

(C) The Author(s) 2019

\begin{abstract}
The PREVENT policy introduced a duty for British health professionals to identify and report patients they suspect may be vulnerable towards radicalisation. Research on PREVENT's impact in healthcare is scant, especially on the lived experiences of staff. This study examined individual interviews with 16 critical National Health Service (NHS) professionals who participated in mandatory PREVENT counter-radicalisation training, half of whom are Muslims. Results reveal two themes underlying the self-censorship healthcare staff. The first theme is fear, which critical NHS staff experienced as a result of the political and moral subscript underlying PREVENT training: the 'good' position is to accept the PREVENT duty, and the 'bad' position is to reject it. This fear is experienced more acutely by British Muslim healthcare staff. The second theme relates to the structures which extend beyond PREVENT but nonetheless contribute to self-censorship: distrustful settings in which the gaze of unknown colleagues stifles personal expression; reluctant trainers who admit PREVENT may be unethical but nonetheless relinquish responsibility from the act of training; and socio-political conditions affecting the NHS which overwhelm staff with other concerns. This paper argues that counterterrorism within healthcare settings may reveal racist structures which disproportionality impact British Muslims, and raises questions regarding freedom of conscience.
\end{abstract}

Keywords United Kingdom · Prevent · Self-censorship · Healthcare professional · Racism $\cdot$ Radicalisation $\cdot$ Muslims

Tarek Younis

younis.tarek@gmail.com

1 Division of Psychiatry, University College London, 6th Floor, Maple House, 149 Tottenham Court Road, London W1T 7NF, UK

2 Cross-Cultural Psychiatry, Division of Psychiatry, University College London, London, UK 


\section{Introduction}

The UK government first developed its overarching counter-terrorism strategy, CONTEST, in 2003 as a response to the attacks in New York and Washington D.C. on 9/11 (Omand 2004). At the time, CONTEST's focus was simple: develop a cohesive pan-Governmental strategy to protect the UK from terrorist threats. This involved the establishment of four sub-strands, three of which (Protect, Pursue, Prepare) involve the management of actual terrorist attacks. A fourth strand, PREVENT, seeks to pre-emptively deter individuals from supporting or engaging in terrorism through a process called 'radicalisation'. Following the 7/7 attacks by British-born terrorists in 2005, the UK government expanded its PREVENT policy to focus on anti-radicalisation measures to prevent further incidents. To this effect, the UK government integrated its PREVENT strategy into the National Health Service (NHS) in 2011 as a statutory duty for all healthcare staff to identify and report those vulnerable to radicalisation (HM Government 2011). In 2015, the newly integrated PREVENT policy became a statutory duty. The government now designates the NHS a 'pre-criminal space' in its healthcare guidance (HM Government 2015). British healthcare staff are currently trained in counterradicalisation within the purview of safeguarding, placing radicalisation alongside other safety concerns such as child abuse.

PREVENT is widely recognised as controversial (Lewis 2018) and there exists a growing body of literature critical towards the policy (Kundnani 2014; O'Donnell 2016; Ragazzi 2017). The Extremism Risk Guidance framework upon which NHS staff are trained to detect vulnerability to radicalisation has been subject to widespread academic criticism (Ross 2016). In the absence of a robust evidence-base, PREVENT's construction of pre-criminality appears to have followed political developments first and foremost (Bail 2015). Previously, under Labour, PREVENT was discovered to have focused predominantly on neighborhoods with large Muslim demographics (Kundnani 2009). Its current iteration under the Conservative-led government, which introduced PREVENT as a duty within the NHS, follows the logic of 'big data'; the risk of terrorism is thought to exist in everyone, thereby justifying population-wide counter-radicalisation training and surveillance (HeathKelly 2017). In turn, major public organisations such as the National Union of Teachers (Rights Watch UK 2016:12) passed a motion rejecting PREVENT, stating teachers "have no wish to be ancillary members of the security service." The British Medical Association has also recently backed a motion to support doctors who choose not to engage with PREVENT based on the argument the policy leads to racial profiling (Iacobucci 2018). In view of these developments, one might expect PREVENT to pose concerns for healthcare professionals by virtue of its controversy alone. Yet there is virtually no research documenting the lived experiences of health professionals now obligated to screen patients for potential vulnerability towards radicalisation. 


\section{Purpose of this Article}

Little is known how healthcare staff perceive the PREVENT policy or indeed understand their counter-radicalisation duty, despite the fact training has now been completed over one million times in healthcare settings (Taylor 2018). The only empirical study available includes a survey with 329 NHS staff across the Midlands (Heath-Kelly and Strausz 2018). Results reveal that NHS healthcare professionals differ significantly in their attitudes and understanding of PREVENT policy and the concept of radicalisation. In matters where health practice is increasingly regulated by the State (Walshe 2002), it is pertinent to question the extent to which critical healthcare professionals feel capable of resisting state regulation. For reasons outlined below, all healthcare staff interviewed in our research were critical of their PREVENT training in some form or another. The purpose then is not to critique the PREVENT policy directly but to examine what it means for NHS professionals to be critical of state policy, which we explore with the following questions.

Research questions:

1. How do critical NHS staff experience PREVENT training? Do Muslim and nonMuslim staff experience training differently?

2. Do critical NHS staff voice their concerns with PREVENT during training? If not, what are the factors preventing them from sharing their concerns? If they do share their concerns, what are the factors facilitating this?

\section{Methodology}

The data for this paper was taken from a larger, community-based ethnography exploring the impact of the PREVENT policy in the NHS, addressing both healthcare professionals and British Muslim people's narratives. Ethical approval for this research was granted by the UCL Research Ethics Committee (REC).

\section{Participant Recruitment and Characteristics}

Our cohort consisted entirely of NHS staff who dissented - to varying extents and not equally - with the PREVENT policy. This was not by design, nor was it random. The moral dimension of counter-terrorism makes the subject difficult to discuss (see Stampnitzky (2013) for a history of counter-terrorism discourse). Our fieldwork was at times challenging. For example, some healthcare professionals admitted they preferred not to engage in politically sensitive subjects. Their reluctance was exacerbated by the limited time they have to engage in research and many are overburdened with work (Carey et al. 1996). Healthcare settings also rely heavily on trust (Gabbay and Le May 2010). Staff may have been apprehensive to speak with outsiders about sensitive issues affecting their practice. Though recruitment flyers were shared via listservs-public and within several closed General Practitioner professional networks - all participants were ultimately recruited via snowballing, which indeed is encouraged in health practitioner research (Carey et al. 1996). 
Snowballing has the advantage of being able to rely on informal networks of trust during recruitment but poses the challenge of drawing from a particular set of participant characteristics. In our cohort, we witnessed two identifiable participant characteristics which we suspect influenced the decision to participate: (1) holding a critical outlook towards normative or Eurocentric healthcare models and (2) belonging to an ethnic minority background. We must note however that many participants still shared some discomfort in sharing their training experiences, and so interviews generally proceeded after repeated promise of confidentiality, anonymity and the opportunity to read a draft of this manuscript before publishing. Recruitment and interviews took place between November, 2017, and July, 2018. ${ }^{1}$

The War on Terror has marshalled a securitisation of Muslim bodies. We relate thus to the distressing experiences of British Muslim staff as a form of racism (Poynting and Mason 2006). Considering the PREVENT policy's implicit and explicit emphasis on British Muslims in particular (Coppock and McGovern 2014), participant recruitment ended when we felt we had a balance between Muslims and participants of other faiths/non-faith. We did not specify any profession in our recruitment, although most of our participants were psychiatrists. The Royal College of Psychiatrists (2016) is the only professional health organisation to have issued a statement on PREVENT policy at the time of writing this paper. For the sake of confidentiality and anonymity, participants characteristics are limited to Profession, Gender, General Location, Ethnicity and Religion (see Table 1), as agreed with participants themselves. Ethnicity itself is divided in the following three categories: White or ethnic minority, whereby Muslim is added as an additional qualifier should the participant self-identify as Muslim. These choices were necessary to protect the identity of the NHS staff while maintaining the necessary details relevant to the research questions.

\section{Data Collection}

Interviews lasted between $30 \mathrm{~min}$ and $2 \mathrm{~h}$ and were carried out in person as well as over phone. During the informed consent process (sent and signed via email for telephone interviews), we acknowledged the sensitivity of the research subject, affirmed anonymity, and informed participants of the option to withdraw. Interviews were transcribed using an external transcription service.

In keeping with the exploratory nature of the research, we promoted a nonthreatening, two-way dialogue to solicit an organic narrative. A semi-structured interview guide was used in an open-ended format, focusing on experiences of PREVENT training and its translation into practice.

\footnotetext{
1 A reflexive note on positioning: the primary author is a racialized BME mental health professional with a clinical background. Thus, he is positioned by the PREVENT policy as much as he seeks to explore its impact on others; this racialized positioning is significant in the politicised space encompassing researcher and participant.
} 
Table 1 Participant characteristics

\begin{tabular}{llllll}
\hline Pseudonym & Profession & Gender & Location & Ethnicity & Religion \\
\hline Adam & Psychiatrist & Male & Midlands & Ethnic minority & Muslim \\
Amy & Psychiatrist & Female & South & Ethnic minority & Non-Muslim \\
Fatima & Psychiatrist & Female & North & Ethnic minority & Muslim \\
Hafsa & Psychiatrist & Female & South & Ethnic minority & Muslim \\
Harrison & Psychiatrist & Male & South & White & Non-Muslim \\
Jack & Psychologist & Male & South & White & Non-Muslim \\
Jessica & Psychologist & Female & South & Ethnic minority & Non-Muslim \\
John & Psychiatrist & Male & South & White & Non-Muslim \\
Khalid & Psychiatrist & Male & South & Ethnic minority & Muslim \\
Maryam & GP & Female & North & Ethnic minority & Muslim \\
Michael & Psychiatrist & Male & South & White & Non-Muslim \\
Nadeem & Manager & Male & South & Ethnic minority & Muslim \\
Neumann & Psychiatrist & Male & South & White & Non-Muslim \\
Sara & Psychologist & Female & South & White & Non-Muslim \\
Susan & GP & Female & South & Ethnic minority & Non-Muslim \\
Yaqeen & Psychiatrist & Male & South & Ethnic minority & Muslim \\
\hline
\end{tabular}

\section{Qualitative Analysis Strategy}

A thematic content analysis was used to discover patterns within the narratives (Braun and Clarke 2006). A contextualized approach was used to address both the meanings individuals extrapolated from their experiences, as well as context which formulated the boundaries in which meaning could be constructed. Our analysis primarily emphasized themes relating to experiences of PREVENT training, and the ability in sharing these experiences with others. Two researchers coding separately found a high degree of consistency in extrapolated themes. Themes were then categorized and linked to the overall research objectives. A mind map was developed connecting themes to particular social contexts.

\section{Results}

We identified two overarching themes associated with the silencing of critical healthcare staff during PREVENT training.

Theme 1: Fear and morality intrinsic to PREVENT training

Theme 2: De-politicization exacerbated by structural issues within the NHS 


\section{Theme 1: Fear and Morality}

A group of mental health professional dedicated one of their recurrent gatherings to discuss the PREVENT policy. An attendee shared their experience with PREVENT: their NHS training went its usual course until the trainer suddenly introduced the PREVENT policy. Surprised, the attendee had raised their hand and questioned why they were being trained in counterterrorism. To this, a colleague turned to them sternly and said, "We're just trying to save lives." The attendee was stunned. (first author, fieldnotes, May 12th, 2018)

This vignette highlights the exact moment an NHS professional realized PREVENT training was morally charged. Though PREVENT packages counterterrorism as an extension of normative healthcare practices, it determines a novel moral boundary for NHS staff: the morally good position is to accept counterterrorism policy in healthcare, and the morally bad position is to reject it. The explicitness of such a moral boundary is indicative of an atmosphere of fear which Susan, a white female General Practitioner, experienced in PREVENT training (some phrases have been removed to preserve anonymity):

Susan: And my worry is I'm frightened. I'm frightened of putting my head above the parapet... I've been asked to sign [redacted]. I'm frightened. I'm frightened of naming myself. I have spoken to various people, including my own professional body to say what they [the Home Office] are doing. They're aghast about it all, but they're not getting involved, so there is a collusion of anonymity.

TY: What is it you're frightened of?

Susan: I'm frightened I'll be targeted by the political powers. I'm frightened I'll be attacked in the press, that I will be excluded, that I will be taken to be a terrorist friend and that it will be completely misconstrued."

For Susan, vocal criticism to PREVENT training is paramount to being seen as a terrorist sympathiser. Amy, a female minority psychiatrist, revealed:

The whole feeling in the room, at the end of the day, was 'this was great'. It was horrifying... I was completely unable to ask a question: is radicalisation amongst white skinheads as big a problem for society as, say, a young, brown, Muslim person?

Amy shared her apprehension with the PREVENT policy, stating it was largely a racist policy which targeted Muslim populations first and foremost. White extremism, she says, was added as an afterthought.

Our Muslim interlocutors shared a unique anxiety about speaking out during PREVENT training, fearing their criticism will associate them with the very thing ('radicalisation') their training seeks to impede. Maryam, a Muslim General Practitioner, shares her thoughts on the sort of responses she's received for being critical of PREVENT on social media: 
It's almost like, if you're anti-PREVENT, you must be pro-terrorism. 'Admit you're a terrorist sympathiser.' That's the other one I've had. 'You're a terrorist sympathiser.' Well, no, because the two are totally separate.

Maryam reveals it's been difficult navigating the moral salience of the PREVENT duty, and the moral distress the policy has caused her. She later adds:

You've always got to think that when you speak out. Will you face any consequences for challenging what people are taught - which is absolutely ridiculous - or challenging referrals that are incorrect? Will there be any repercussions to me? Whereas, all I'm doing is trying to protect my patients from being wrongly accused of things that they shouldn't be and not getting the healthcare that they need?

Adam, a Muslim psychiatrist trainee, was not as vocal as Maryam on social media but just as apprehensive. He shared his account of PREVENT training, and why he felt incapable of sharing his thoughts:

There was a fellow Muslim who was there [with me during training] and we would often look at one another. It's almost as if they are in a position of power - obviously with responsibility comes the power - but how would we react if we were at the receiving end of a referral? And it felt on any given moment - I'm commenting on behalf of myself - that I could be at that receiving end. I'm not the person who's making the referrals but I'm the person people are referring to PREVENT, for example. [...] But for me it is that kind of, to reiterate, the consequences of being critical. And it's just, you don't feel safe. You don't feel safe, it's just... you don't feel safe. You don't feel that your colleagues wouldn't report you. [...] There is tension during that training session, because you don't know if they might be glancing at you and treating you as if you belong to that [extremist] group. [...] The whole week I remained silent, I didn't want to attract attention. I haven't given it much thought as to why I remained silent throughout. It might be institutional racism. I don't know. But I just wanted to emerge from that training session unscathed as best as I could.

Even vocal Muslims were made aware of the boundaries of allowable speechand its associated culture of fear-when they raised their concerns. Fatima, a psychiatrist trainee, recalls having cited the Royal College of Psychiatrist's statement against PREVENT during training. This prompted a small exchange within the group but was soon forgotten afterwards. Several weeks later, Fatima was told that her trainer had lodged formal complaint against her (though she wasn't the only one to raise concerns during training, she affirms she was the only Muslim) and that an external mediator was summoned to evaluate the trainer's grievance. Several individuals across the managerial ladder were involved in the investigation andmuch to Fatima's surprise-the trainer's formal complaint contained statements Fatima never made, such as a reference to the Muslim Council of Britain. The mediator never consulted Fatima for her side of the story. In the aftermath of this complaint, Fatima had this to say about her colleagues: 
The reaction from everyone [Fatima's colleagues] who was white was to immediately say: 'if you want any help with anything, we'll write anything that you need. If there's some kind of investigation going on and you need a character statement or anything.' [...] And everyone who was Muslim and non-white, their reaction was: 'why did you say anything?' Their reaction was one of horror and disbelief. Not at what happened, but horror and disbelief that I had said something in the training - like, 'how stupid can you be?'

This idiosyncratic incident showcases how deeply ingrained fear and selfcensorship may be embedded among British Muslim NHS staff in particular.

Not all critical participants experienced fear during PREVENT training. Jack, a white male psychologist, though recognizing how the PREVENT policy casts Muslims with suspicion, had this to say about his experiences during training:

It [PREVENT training] felt a bit like fire training, this is what it is. They've got to give you these slides. We've got to talk about what to do, in case of a fire. There are the different sorts of fire extinguishers. This is what they look like. This is how they work.

Jack took issue with the PREVENT training but did not air his grievances; not out of fear, but simply for its banality- like fire training.

\section{Theme 2: De-Politicization Exacerbated by Structural Issues Within the NHS}

Though fear was significant in inhibiting critical healthcare staff from expressing their thoughts, some were still likely to voice their concerns. Here we explore structural conditions impacting the capacity to voice dissent: the distrustful setting, the reluctant manager and the socio-political conditions of the NHS.

\section{The Distrustful Setting}

Nine participants received PREVENT training among professionals comprised randomly of healthcare staff across their NHS Trust, four participants received training within their own specialised mental health teams, and one psychologist participated in both settings (a final participant took their training online, which will not be discussed). The seemingly benign discrepancy between general/team played a critical role in the incidence of self-censorship.

Adam, the psychiatrist who spoke about leaving the general PREVENT training unscathed, had more to say about the importance of trust:

I don't want to make myself vulnerable, I don't want any situation where I have a superficial relationship with people and then discover that actually, 'no, they might be sympathetic to the government PREVENT policy and they might believe that it's appropriate for Muslims to be referred to PREVENT.' And then that would upset me. And I want to protect myself. 
In Adam's case, it's clear the fear is made worse in a setting where fellow trainees are unknown, and their gaze is met with unease. Adam later explained he tends to be more vocal with regards to referrals in clinical discussions, where he finds it important to advocate on behalf of Muslims patients:

I've noticed that when it comes to kind of teaching and training, I tend to be more reticent because I feel as though people are looking at me through a lens of suspicion.

But such discussions occur within teams, which reveals the extent to which trust and security is foundational to resistance.

Jessica, a minority female psychologist, is the only participant who received two PREVENT trainings in quick succession: once general, then again with her teamboth the same trainer. In the first instance, Jessica learned of PREVENT as part of the larger NHS Trust's safeguarding training. She says anger was the most prominent emotion she experienced during training. When questioned why she didn't share her anger during the session, she admits: "I think it was partly because it was a larger group, and it was people I didn't know." Here Jessica reveals why she withheld her thoughts: she was not acquainted with any of her colleagues during training.

This soon changed when Jessica's manager informed her the PREVENT safeguarding lead will present a more extensive session for the psychologists in the team. Jessica confronted the manager and questioned why she had to retake the same training, stating the policy was offensive and should be challenged. The manager insisted 'it was mandatory', ending the discussion. Jessica said she regrets not pushing the matter further, knowing others had refused the training on 'moral' grounds. Jessica thus re-attended the training:

She [the trainer] gives us a vignette, [...] just describing a religious Muslim boy, but it was framed as though it should be a safeguarding issue. At that point, I felt like I wanted to cry because I felt so outraged and angry and upset. And I felt as though I wanted to tell the team how I was feeling in my body because it feels like we are being encouraged to disconnect from our bodily responses to things. [...] I just said, 'I find this really offensive because basically you're encouraging us to see being religious, being religious as a Muslim person, as equivalent to having extreme views'."

There is much to be said about Jessica's experiences, especially with regards to self-censorship and how she perceived others might belittle the significance of her emotional response. Jessica draws our attention to the racial and gendered elements at play between colleagues (Jessica later admitted she was afraid of playing the stereotype of 'the angry, black woman' in front of her colleagues). However, Jessica managed to 'intellectualise' (her word) and voice her concerns because she knew everyone on the team. Having experienced the same PREVENT training twice, Jessica remarked how important it is that "training could be provided to teams where there could be some kind of safe space for discussion."

The strangeness of the training group was also raised by Neumann, a white male psychiatrist. Having shared his ethical concerns with PREVENT training, he adds: 
These were my thoughts. I don't know what the others thought... but I could never have a discussion. I can discuss it with friends, if you know them. [...] So, I didn't ask anyone, and I had not a chance to speak of this [PREVENT] with anybody. Now it's more than six months I'm working here.

Neumann thus reiterates the importance of trust and familiarity in being able to share one's thoughts during training and, moreover, with colleagues afterwards. For Neumann, the absence of these elements meant he kept his concerns about PREVENT to himself ever since he began work 6 months prior to our interview.

\section{The Reluctant Trainer}

The reluctant trainer relates to the perception that trainers are simply mediators/ actors following institutional scripts-individuals simply 'doing their jobs.' In our fieldwork, the silencing of dissent was sustained through the perceived reluctance of safeguarding leading to provide PREVENT training. This theme took two forms. The first considers how little an impact an ethical complaint raised towards a reluctant PREVENT trainer will have. Here participants see the trainer as a cog within the larger policy apparatus. To share one's worries about PREVENT would be akin to raising concerns with an automaton, to which Adam shares his sympathies:

I am sympathetic to the trainer who I know because they have been delivering safeguarding training for years. And I know what happens when they get told by someone pretty high up that on this year's agenda we have to cover WRAP [Workshop to Raise Awareness of PREVENT].

Another example of the reluctant trainer was given by Michael, a white male psychiatrist, who had this to say when questioned why he didn't raise any complaints during PREVENT training:

I didn't [raise a complaint] partly because I got the impression the guy [the trainer] was reading from a script, and you don't shoot the messenger. [...] And he sort of presented [PREVENT] that way as well - disassociating himself from some aspects of the talk.

Jessica questions why the trainer ought to encourage open discussion despite its public controversy:

How could you on the one hand say it's important that people speak up and say something? But yet you're delivering the training as though it is something that we should be doing, (a) that we should be doing it, and (b) that there's no issues with it, and it's not oppressive or harmful to people.

For John, another white male psychiatrist, the automation of the entire training process was distressing:

I asked him [the PREVENT trainer]: 'Why are you telling us to do this here?' And his reaction was just, as you say, introducing it into the realm of the normal - unquestionably so. [The PREVENT trainer] is just saying that, well, 
he's just here to do the training. And this is what is now required, that we are trained on this. [...] And that was it.

And I did raise, also, a few questions about the claims about evidence. You know, just basic questions: how on earth could we do this without putting at stake our rapport and trust with patients? But in the room, you don't get much feedback. This is what was even more depressing: people seemed to, kind of, just go along with it.

Fatima shares a similar experience with her trainer following the PREVENT session:

The one person that was delivering it said this to me afterwards, [PREVENT] was not something that he particularly wanted to do, or it was just something that he had been told that had to be done. And all he was doing was reading from the sheet or whatever it was they were told to do. And he couldn't answer any of the questions that... You know, he was quite apologetic about it.

The trainer's apology for giving PREVENT training presents the second form of the "reluctant trainer": when trainers themselves recognize PREVENT may pose ethical concerns, but admit feeling compelled to follow the script they are given. Though these instances are exceptional, their significance merits attention.

Jessica, for example, corroborates Fatima's experience:

What I found interesting, frustrating and strange is that she [the trainer] was agreeing with people. She was saying, I have to give this training, but I totally agree with you: it is outrageous. [...] And she's saying, 'well, I completely agree, and it is Islamophobic, and it is targeting a community, and it's important that we have this conversation, that why we're talking about this, but here it is: it's mandatory. I have to give this training.' [...] I and a few other people raised concerns about confidentiality, accountability, the lack of evidence-based.

What is the use of being critical, Jessica argues, if trainers are simply unwilling ambassadors of an enterprise they recognize to be unethical, and the responsibility for PREVENT is deferred elsewhere?

\section{Austerity and the Overworked Mind}

NHS services are presently fraught with issues outside of the PREVENT policy. There is limited time and attention professionals can devote to personal and ethical concerns in the current healthcare climate, as Jack later explains:

My view [is] that $99 \%$ are just going to ignore this stuff. In my job, in particular, there are lots of things which I could potentially do, and you have to pick what you're going fight for, if you know what I mean. I've got other roles where I have to make those decisions where I'm going to try and do this in my job. So, I didn't pick that one [PREVENT] to have a fight about. [...] And everyone seems to be ignoring it, so let's get on and worry about some other things. Perhaps wrongly. 
Austerity played a big factor for Amy, the minority female psychiatrist. As a consultant and a manager of a large team that experienced significant cuts, her story is especially revealing:

The fact that that service itself, those nurses, had been subject to a cut of $80 \%$ that very month, and they were now focusing on PREVENT. I actually made some notes at the time, I was so shocked: that was the last session we had supervision [before the cut]. [...] All those nurses who sat in supervision were jobless about eight weeks later.

Amy was surprised how her nursing team, during clinical consultation, eschewed an adolescent's ongoing experience of severe domestic abuse to discuss the possibility of radicalisation. This happened shortly before the nurses lost their jobs because, as Amy explains, "in the face of literal breakdown of a service and people losing their jobs - and there are no patients or clients to look after-you worry about things that don't exist, like possibilities of radicalisation." Amy then deliberates over how she sees PREVENT fit into the increasing privatisation of the NHS:

Making things accountable, rather than transparent, is actually what drives many of the developments in healthcare. In the twenty years that I've been a psychiatrist, particularly in the last eleven years that I've been a consultant and in charge of a service, with every cut that we've had, I have seen further investments in things. Not just PREVENT, but things like patient satisfaction managers, complaint managers, in the managerial culture that sets itself up to account for the activities of dwindling clinicians. And I actually see the decline of the NHS services as a direct result of counting measures.

Amy explains how austerity and the privatisation of the NHS has led to the overregulation of healthcare practice. To maximise efficiency with fewer staff, the NHS has increased its purview to 'account' for every element of professional autonomy. The increasingly overworked healthcare professional, according to Amy, is less interested in the patient and more concerned with institutional evaluation of their performance. Amy fought tooth and nail against budget cuts and managerial pressure, but "speaking up is not necessarily very welcomed; this is the culture of the NHS, across the board." She even says she had exhausted her "complaint tickets', having struggled with an incident of a trainee who experienced racism. Finally, she says, "by the time PREVENT training came, [her] physical experiences sitting in the room was... shattered," and she withheld challenging the policy.

Neuman, the white male psychiatrist from abroad, explains why he withheld sharing his dissent during training:

I didn't make any criticism [during PREVENT] because you have to begin the job, so this is compulsory training. And they say that, if you want the job, you have to accept everything. So, the atmosphere was, 'you have to do this, it's part of the job.'

This segment outlined Neuman's NHS experiences since his arrival to the UKyou have to accept everything you are told. 
Another white male psychiatrist, Michael, admits there's just too many other things to think about during clinical practice to raise a specific concern with the PREVENT policy:

It [the PREVENT policy] seems rather irrelevant to our real work and what we're really concerned with, as doctors. The colours of the fire extinguishers aren't stuff that are a mandatory training. So, I was slightly taken aback that this was just presented as a kind of standard safeguarding thing for us. I'm concerned about the institutionally racist sort of way that it was presented to us.

Similarly, Michael presumed the greatest danger PREVENT posed to the NHS was that healthcare staff are largely apathetic to controversy due to overwork, and many will regurgitate policy uncritically. As Susan, white female GP, put it:

My concern is that the staff in the NHS are very, very, very compliant and if there is a greater emphasis [on anti-radicalisation] they will do what they're told to do; then there will be compulsory training, and then compulsory targets. And it will become a self-fulfilling prophecy.

\section{Discussion}

Our critical cohort of 16 participants raised a number of concerns with their PREVENT training. Healthcare professionals should feel comfortable sharing concerns with policy as they arise. Otherwise, self-censorship may have significant impact on treatment as well as enjoyment of work (Lamiani, Borghi, and Argentero, 2017). One of the central concerns raised in this paper was the experience of fear made salient by the moralising dimension intrinsic to PREVENT training, which has a disproportionate impact on Muslim staff. At the same time, it appears the context surrounding the training module - the trainer, other participants in the room, what else is going on in the NHS-equally contributes to self-censorship. We posit that the interaction of all these factors within the experience of PREVENT training is unique and combine to produce a silencing effect that is more than the sum of its parts.

\section{Dynamics of Silencing: Fear, Morality and Race}

Our interviews provide a glimpse into the geopolitics of fear in healthcare settings as a result of the War on Terror. The political employment of fear ("a terror threat is imminent") to justify increasingly intrusive policies, whereby the State simulates an impression it can predict the unpredictable, has led some scholars to call the counter-terrorism enterprise a War of Terror as much as it is on it (Pain 2009:467). Unsurprisingly, fear plays a significant role in self-censorship. For example, the fear of losing one's employment is also known to be the result of state repression (Boykoff 2007:289). Stigma is one mode through which this fear operates. As Goffman (1963:3) explains, stigma can be conceived as a special relationship which 
exists between an attribute and an excluded 'other', normalised in a political hegemony which differentiates 'Others' from 'Us.' Individuals demobilise and selfcensor these stigmatising attributes in fear of being associated with the 'Other'. In PREVENT training, the stigmatising attribute - the moral quality dividing us and them, good and evil-is the very act of critiquing counter-terrorism policies. Indeed, UK Home Secretary Sajid Javid has recently likened dissenters of PREVENT with extremism (Hymas 2018).

Debates surrounding health practices have always involved political and moral arguments (Pushkar 2018:2). For PREVENT however, we locate its moral dimension within the enterprise of counter-terrorism. This follows Stampnitzky's genealogical analysis of 'terrorism' as an object of study: since the beginning of terrorism studies, anyone speaking against State-led narratives of counter-terrorism has feared the stigma associated with being critical-including renowned counterterrorism experts (Stampnitzky 2013:191). Thus, the fear of sharing ones concerns with PREVENT — and potentially provoke State and public reproach - is not unique to our cohort. Emerging research on the impact of Prevent has found that highschool students (Busher et al. 2017) and university students (Scott-Baumann 2017) are increasingly censoring their views out of fear as well. Thus, the moralising dimension within PREVENT training transcends spaces and is not limited to healthcare.

The concept of 'risk', Beck argues (2002:40), controls the present in its attempt to calculate the future. In theory, one may argue that the moral dimension of PREVENT training is inevitably associated with the need to convey the importance of preventing future attacks. In practice however, the moral logic of PREVENT - to prevent a future catastrophe-also serves to regulate a boundary between 'correct' and 'incorrect' modes of clinical practice in the present. To do this, PREVENT packages its logic of risk detection under "safeguarding", alongside other social ills such as child abuse. The framing of PREVENT as "safeguarding" is significant in this regard; dissent connotes an additional moral dimension of being lax or supportive of abuse. Unsurprisingly then, most participants stated their teams underwent PREVENT training with little to no vocal resistance, though they might later share their discontent within trusted groups using encrypted social media platforms such as WhatsApp. However, when offered the cover of anonymity, Heath-Kelly and Strausz (2018:45) found that, of 329 respondents, the majority of NHS staff they surveyed were either unsure or disagreed with PREVENT's framing as safeguarding. There are two possible reasons for this. First, the Care Act (2014) stipulates that an adult safeguarding referral must necessarily involve an individual whose autonomy is impaired in some form, and whose impairment subsequently make them vulnerable to abuse. An example of this might be that of an elderly man suffering from early-onset dementia, lacking in his capacity to make decisions. Yet there are documented cases of adult PREVENT referrals involving professionals such as teachers-people whose autonomies are normally not deemed safeguardingworthy (Wooding 2018). Second, PREVENT is exceptional in its safeguarding frame in that it involves individuals who may not only be at risk from others, but definitively a risk to others in the future. Here the convergence of pre-criminality and safeguarding sits awkwardly. In making a referral, are we protecting the 
individual or society? If it's society, then this overlaps significantly with the purview of the criminal justice system. And if it is the individual, why are the police involved?

Notwithstanding the notion of pre-criminality is distinctly racialized in public consciousness. Thus, while anyone may experience fear and discomfort during PREVENT training, these feelings are amplified among critical Muslim staff. Muslim participants relate how PREVENT augmented the consciousness of their own racialized bodies during training. Some even shared their fear of ending erroneously at the tail-end of a PREVENT referral themselves (as has happened in several cases, see Forster 2016). The experiences of Muslim NHS staff highlight the racialized element embedded within the counter-terrorism discourse. Terrorism and all its affiliated connotations, such as radicalisation, are known to be deeply racialized in public consciousness towards bodies which appear "Muslim" as the locus of security concerns (Martin 2014). This is especially relevant in a post-Brexit era, whereby many argue the referendum succeeded largely on the Leave campaign's ability to draw upon long-standing forms of latent racism (especially with regards to the Muslim 'other') in public consciousness (D'Orazio and Salehyan 2018; Virdee and McGeever 2018). There is thus the added political pressure for our Muslim healthcare participants to appear as 'good Muslims'-conforming and obedient to State policy (for a discussion, see Mamdani 2005; Morsi 2017).

At the juncture of the securitisation of Muslim bodies and the moral fear of dissent, Adam repeated the anxiety-laden “you don't feel safe, you don't feel safe, you just don't feel safe". Unsurprisingly, Adam likened PREVENT training to a room on fire; his only desire was to escape 'unscathed'. Such experiences speak not only to the practice of self-censorship but indicates larger concerns of institutional racism within healthcare that are especially distressing for its minority members of staff. Not all our British Muslim participants exercised self-censorship, but they all recognized to varying extents the overtly racialized field healthcare settings have become. Here one must question to what extent the NHS evaluates and addresses the racial implications of the policies it enforces, not only with regards to PREVENT but other policies as well (Fernando 2017). This is not to say PREVENT training was equally paralysing across my British Muslim participants. For example, I encountered a British Muslim NHS member during fieldwork who admitted joining PREVENT to mitigate for its racism towards Muslims. Thus, one must also acknowledge that the experience of racism can be mobilising, pulling individuals closer to the institutions where such experiences are to be found.

\section{Dynamics of Silencing: The Setting}

Fear is not simply a psychological phenomenon; the emotional reaction must be localised particular to its social and spatial contexts (Pain 2009:467). Though we argue that fear is PREVENT training's most salient feature among critical staff, it synergises with other structural elements in the NHS to produce a silencing atmosphere. Among our cohorts, PREVENT training took place in one of three environments: general within the NHS, team-specific and online. General safeguarding training took place in a room with strangers from other divisions 
within the NHS trust, many of whom our participants might never encounter again. Participants in general training shared their apprehension of revealing their wellintended concerns beneath the Lacanian 'gaze' of strange colleagues, where any mistake in verbal communication might result in institutional repercussions. At the same time, our five participants who received team-specific training admitted feeling safe to speak out their minds in the comfort of their friends and colleagues. This distinction is unsurprising, as trust is known to play an integral role in healthcare settings (Gabbay and Le May 2010).

At the nexus of concerns with PREVENT training is the trainer themselves. Several of our participants reiterated their dismay with the fact their trainers appeared to regurgitate State-sanctioned scripts unquestioningly (these scripts can be found online, e.g. HM Government 2016). Our participants thus perceived the trainer as an extension of government politics within the NHS. This brought the agency of the trainer often to question. When a trainer told John "he's just here to do the training," the message was clear: the trainer is not responsible for PREVENT, and so the critique of training is futile. Above all, the greatest worry for participants arose when trainers themselves admitted PREVENT was racist- but delivered the training anyway. The reality there are trainers who reluctantly actualise a policy they acknowledge to be racist raises significant ethical concerns within the NHS. Butler (2004:56) relates to such trainers as 'petty sovereigns'; bureaucratized figures mobilized to enact the aims of the institution, without any real power to think or act for themselves. Indeed, research in healthcare management has found that training has increasingly become an exercise in 'soft power', whereby behaviours are to be managed directly via training (Jones 2018). The occurrence of reluctant trainers/petty sovereigns raises significant ethical concerns over how perceived unethical policies may be 'banalized' within bureaucratic systems in which staff are tasked to 'play' their parts.

NHS staff are not immune to the increasingly unstable political and economic climate. As NHS services are broken down and over-regulated within the auspices of increasing privatisation, staff are mobilised on concerns of budget cuts and job insecurity (Pushkar 2018). However, as our participants reveal, it's impossible to mobilise on all concerns plaguing the NHS. When Amy spoke of feeling shattered by the state of the NHS, the PREVENT policy was certainly not the cause of this. For her, it was simply the final straw that broke the camel's back. Healthcare privatisation instils an environment in which service efficiency is expected to remain the same while cutting costs. To achieve this, more managers are hired to regulate healthcare provision in the face of increasing cuts and underfunding (Baines and van den Broek 2017). PREVENT training brings to light how little critical healthcare staff can manoeuvre within an increasingly over-regulated and under-funded environment. The PREVENT policy simply becomes an additional checkbox among an increasing number of regulatory practices. Thus, though the participants may find PREVENT concerning, it must find a place among a myriad of other professional worries. As Amy admitted poignantly, she did not take a vocal position on PREVENT during training as she felt she had simply exhausted her 'complaint tickets'. Though Amy might choose one 'ticket' over another, this begs 
to question how healthcare staff are depoliticised in their ability to address other concerns they may have.

\section{Prospective Research and Limitations}

As this ethnography was largely exploratory, its purpose was to open avenues for prospective research with regards to the impact of counter-terrorism policy in healthcare. First, as a function of our results, we argue that researchers should engage with a theme hitherto unexplored in studies on PREVENT: moral distress. Moral distress is defined as the experience of being proscribed a course of action one deems unethical (Mareš 2016). Our results beg the question: does the PREVENT policy cause moral distress among critical healthcare staff and even PREVENT trainers? So far, none of the studies in a review of moral distress literature have examined this (Lamiani, Borghi, and Argentero 2017). We argue that the nation-wide PREVENT policy is a fruitful avenue to explore this question further. Second, future research should consider how online PREVENT training impacts professional autonomy. We would argue, based on our own fieldwork data, that healthcare professionals might just 'click through' the training although they have ethical qualms with the content. Third, PREVENT's designation of healthcare as a 'pre-criminal space' raises a number of questions about enshrining this term in its policy (Goldberg, Jadhav, and Younis 2016). In the aftermath of PREVENT training, there is little research how the counter-radicalisation duty is translated into practice. What do healthcare staff look out for when assessing for vulnerabilities towards radicalisation? How do PREVENT referrals impact the therapeutic alliance (Rizq 2017)? Fourth, our results indicate the importance of ascertaining staff experiences of perceived racist policies in the NHS, beyond racial hostility (Fernando 2017). Fifth, our findings open new ethical/philosophical inquiries regarding the role of deontological ethics in health care. For example, uncertainty in healthcare decision-making-e.g. at the time of Haemophilia-AIDS crisis-is rectified on the ethical positions of either supporting the common good or the individual good (Wulff 1981). Finally, in the looming shadow of austerity and political instability following Brexit, the NHS is widely recognised to be in a precarious state. All these factors affect healthcare provision, and more research is needed to determine how these socio-political conditions affect freedom of consciousness, and the impact of controversial State health policies on ethnic minorities, including health professionals and communities that place trust in them.

Our ethnographic work is marked by several limitations which prevent it from generalisation. First, as our participants have mostly critical positions towards PREVENT, it necessarily excludes the experiences of staff who may feel neutral or supportive towards it. It is also very well possible, if PREVENT is indeed perceived as a racialized policy, that consenting staff might withhold sharing their consent for fear this might be viewed as racist by their colleagues. Second, we caution from generalising our results outside this limited number of critical healthcare staff. To this, we nonetheless question: are there others who feel the same way? If so, what is an appropriate large-scale approach to documenting self-censorship in healthcare settings? Third, our cohort consisted of a range of various health professions, and 
we did not delineate between them in our analysis. Fourth, we have noticed that PREVENT training sessions may differ significantly in our ethnographic fieldwork (e.g. some might emphasize Far-Right movements more than others). Prospective research would have to account for the varying forms of training, as there are currently over 20 State-sanctioned training modules (HM Government 2016).

\section{Conclusion}

Since its inception, PREVENT has been met by many professionals and organisations with trepidation (Kundnani 2009). Until now, no research has investigated how healthcare professionals might be silenced in their critique of PREVENT. Genuis and Lipp (2013) argue that the freedom of conscience of health professionals must be secured so they may work as independent caregivers and not instruments of the state. The NHS is dedicated to the values of equality, diversity and the eradication of health inequalities. With silenced healthcare staff, the NHS disallows moral safeguards which may prove risky to patients, staff and society. From the role of healthcare staff under Nazi regime to their involvement in the wars in Iraq, Guantanamo Bay (Genuis and Lipp 2013) and Gaza (Cone 2015), the debate surrounding freedom of conscience in healthcare is more important than ever. It is critical healthcare staff should feel secure to voice dissent without fear of institutional or State repercussions.

Acknowledgements We would like to thank the British Academy and the Royal Society for the support and funding of this research through the Newton International Fellowship. We would also like to thank University College London for hosting the project, as well as all our participants for their courage and time in speaking with us.

\section{Compliance with Ethical Standards}

Conflict of interest On behalf of all authors, the corresponding author states that there is no conflict of interest.

Open Access This article is distributed under the terms of the Creative Commons Attribution 4.0 International License (http://creativecommons.org/licenses/by/4.0/), which permits unrestricted use, distribution, and reproduction in any medium, provided you give appropriate credit to the original author(s) and the source, provide a link to the Creative Commons license, and indicate if changes were made.

\section{References}

Bail, C.A.

2015 The Public Life of Secrets: Deception, Disclosure, and Discursive Framing in the Policy Process. Sociological Theory 33(2):97-124.

Baines, D., and D. van den Broek

2017 Coercive Care: Control and Coercion in the Restructured Care Workplace. The British Journal of Social Work 47(1):125-142. 
Beck, U.

2002 The Terrorist Threat: World Risk Society Revisited. Theory, Culture \& Society 19(4):39-55. https://doi.org/10.1177/0263276402019004003.

Boykoff, J.

2007 Limiting Dissent: The Mechanisms of State Repression in the USA. Social Movement Studies 6(3):281-310. https://doi.org/10.1080/14742830701666988.

Braun, V., and V. Clarke

2006 Using Thematic Analysis in Psychology. Qualitative Research in Psychology 3(2):77-101. https://doi.org/10.1191/1478088706qp063oa.

Busher, J., T. Choudhury, P. Thomas, and G. Harris

2017 What the Prevent Duty Means for Schools and Colleges in England: An Analysis of Educationalists' Experiences (p. 69). University of Huddersfield. Retrieved from http://eprints. hud.ac.uk/id/eprint/32349/.

Butler, J.

2004 Precarious Life : The Powers of Mourning and Violence. London: Verso.

Carey, T.S., L. Kinsinger, T. Keyserling, and R. Harris

1996 Research in the Community: Recruiting and Retaining Practices. J Community Health 21(5):315-327.

Cone, J.

2015, July 15 The Humanitarian's Dilemma, https://foreignpolicy.com/2015/07/15/the-humanitariansdilemma-palestine-gaza-doctors-without-borders/, accessed February 11, 2019.

Coppock, V., and M. McGovern

2014 'Dangerous Minds'? Deconstructing Counter-Terrorism Discourse, Radicalisation and the 'Psychological Vulnerability'of Muslim Children and Young People in Britain. Children \& Society 28(3):242-256.

D’Orazio, V., and I. Salehyan

2018 Who is a Terrorist? Ethnicity, Group Affiliation, and Understandings of Political Violence. International Interactions 44(6):1017-1039.

Fernando, S.

2017 Institutional Racism in Psychiatry and Clinical Psychology. New York: Springer.

Forster, K.

2016, November 20 Hundreds of NHS Staff and Patients Referred to Controversial Counter-Terrorism Programme. The Independent, https://www.independent.co.uk/news/uk/home-news/nhs-prevent420-referred-staff-patients-counter-terrorism-reported-scheme-programme-hijab-west-a7428441. html.

Gabbay, J., and A. Le May

2010 Practice-Based Evidence for Healthcare: Clinical Mindlines. Abingdon: Routledge.

Genuis, S.J., and C. Lipp

2013 Ethical Diversity and the Role of Conscience in Clinical Medicine. International Journal of Family Medicine 2013:18. https://doi.org/10.1155/2013/587541.

Goffman, E.

1963 Stigma: Notes on the Management of a Spoiled Identity. New York: Simon \& Schuster .

Goldberg, D., S. Jadhav, and T. Younis

2016 Prevent: What is Pre-criminal Space?. BJPsych Bulletin. 28:96. https://doi.org/10.1192/ pb.bp.116.054585.

Heath-Kelly, C.

2017 Algorithmic Autoimmunity in the NHS: Radicalisation and the Clinic. Security Dialogue 48(1):29-45. https://doi.org/10.1177/0967010616671642.

Heath-Kelly, C., and E. Strausz

2018 Counter-Terrorism in the NHS: Evaluating Prevent Safeguarding Duty in the NHS. University of Warwick, Coventry, https://warwick.ac.uk/fac/soc/pais/research/researchcentres/irs/counter terrorisminthenhs/project_report_60pp.pdf.

HM Government

2011 Prevent Strategy, https://www.gov.uk/government/uploads/system/uploads/attachment_data/file/ 97976/prevent-strategy-review.pdf, accessed October 8, 2017.

2015 Counter-Extremism Strategy, https://www.gov.uk/government/publications/counter-extremismstrategy. 
2016 Prevent: Training Catalogue, https://assets.publishing.service.gov.uk/government/uploads/system/ uploads/attachment_data/file503973/Prevent_Training_catalogue_-_March_2016.pdf.

Hymas, C.

2018, December 1 Prevent Critics “on Side of Extremists,” says Home Secretary Sajid Javid, https:// www.telegraph.co.uk/news/2018/12/01/prevent-critics-side-extremists-says-home-secretarysajid-javid/, accessed January 3, 2019

Iacobucci, G.

2018 BMA is Urged to Back Doctors Who Refuse to Take Part in Government's Prevent Programme. BMJ 361:k2869. https://doi.org/10.1136/bmj.k2869.

Kundnani, A.

2009 Spooked. How Not to Prevent Violent Extremism London: IRR.

2014 The Muslims are Coming!: Islamophobia, Extremism, and the Domestic War on Terror London: Verso Books.

Lamiani, G., L. Borghi, and P. Argentero

2017 When Healthcare Professionals Cannot do the Right Thing: A Systematic Review of Moral Distress and Its Correlates. Journal of Health Psychology 22(1):51-67. https://doi.org/10.1177/ 1359105315595120.

Lewis, J.

2018 Prevent as an Intractable Policy Controversy: Implications and Solutions. Journal for Deradicalization 15:111-150.

Mamdani, M.

2005 Good Muslim, Bad Muslim: America, the Cold War, and the Roots of Terror. Harmony.

Mareš, J.

2016 Moral Distress: Terminology, Theories and Models. Kontakt 18(3):e137-e144. https://doi.org/ 10.1016/j.kontakt.2016.07.001.

Martin, T.

2014 Governing an Unknowable Future: The Politics of Britain's Prevent Policy†. Critical Studies on Terrorism 7(1):62-78. https://doi.org/10.1080/17539153.2014.881200.

Morsi, Y.

2017 Radical Skin, Moderate Masks: De-Radicalising the Muslim and Racism in Post-Racial Societies. London: Rowman \& Littlefield International.

O’Donnell, A.

2016 Securitisation, Counterterrorism and the Silencing of Dissent: The Educational Implications of Prevent. British Journal of Educational Studies 64(1):53-76. https://doi.org/10.1080/ 00071005.2015.1121201.

Omand, D.

2004 CONTEST: A 5-Year Strategy for Countering International Terrorism, http://www.sacc.org.uk/ sites/default/files/documents/contest_2003_report_for_release.pdf

Pain, R.

2009 Globalized Fear? Towards an Emotional Geopolitics. Progress in Human Geography 33(4):466486. https://doi.org/10.1177/0309132508104994.

Poynting, S., and V. Mason

2006 "Tolerance, Freedom, Justice and Peace"?: Britain, Australia and Anti-Muslim Racism since 11 September 2001. Journal of Intercultural Studies 27(4):365-391. https://doi.org/10.1080/ 07256860600934973.

Pushkar, P.

2018 NHS Activism: The Limits and Potentialities of a New Solidarity. Medical Anthropology 2:89. https://doi.org/10.1080/01459740.2018.1532421.

Ragazzi, F.

2017 Countering Terrorism and Radicalisation: Securitising Social Policy?. Critical Social Policy 37(2):163-179. https://doi.org/10.1177/0261018316683472.

Rights Watch UK

2016 Preventing Education? Human Rights and UK Counter-Terrorism Policy in Schools, http://rwuk. org/wp-content/uploads/2016/07/preventing-education-final-to-print-3.compressed-1.pdf. 
Rizq, R.

2017 'Pre-crime', Prevent, and Practices of Exceptionalism: Psychotherapy and the New Norm in the NHS. Psychodynamic Practice 23(4):336-356.

Ross, A.

2016, September 28 Academics Criticise Anti-radicalisation Strategy in Open Letter. The Guardian. https://www.theguardian.com/uk-news/2016/sep/29/academics-criticise-prevent-antiradicalisation-strategy-open-letter

Royal College of Psychiatrists

2016 Counter-Terrorism and Psychiatry. Position Statement, https://www.rcpsych.ac.uk/pdf/PS04_16. pdf.

Scott-Baumann, A.

2017 Ideology, Utopia and Islam on Campus: How to Free Speech a Little from its Own Terrors. Education, Citizenship and Social Justice 12(2): 159-176 . https://doi.org/10.1177/1746197917694183.

Stampnitzky, L.

2013 Disciplining Terror: How Experts Invented ‘Terrorism'. Cambrige: Cambridge University Press . Taylor, D.

2018 Hospice Staff 'Trained to Report Dying Patients as Part of Terror Strategy', https://www. theguardian.com/uk-news/2018/jun/11/nhs-staff-trained-to-signs-of-radicalisation-in-terminallyill-says-whistleblower, accessed September 26, 2018.

Virdee, S., and B. McGeever

2018 Racism, Crisis, Brexit. Ethnic and Racial Studies 41(10):1802-1819.

Walshe, K.

2002 The Rise of Regulation in the NHS. BMJ: British Medical Journal 324(7343):967.

Wooding, P.

2018 March 21 Christian Teacher Dismissed for Saying "God Loves You" to Lesbian Student, https:// www1.cbn.com/cbnnews/world/2018/march/christian-teacher-dismissed-for-saying-god-loves-

Wulff, H.R. you-to-lesbian-student, accessed February 11, 2019.

1981 How to Make the Best Decision: Philosophical Aspects of Clinical Decision Theory. Medical Decision Making 1(3):277-283.

Publisher's Note Springer Nature remains neutral with regard to jurisdictional claims in published maps and institutional affiliations. 